\title{
PENDIDIKAN SAUDARA KAPUSIN GENERASI BARU Pelaku Aktif dan Inspiratif di Zaman Aktual
}

\author{
Largus Nadeak* \\ Program Studi Ilmu Filsafat, Fakultas Filsafat, Unika Santo Thomas \\ Email: Gonzales.nadeak@kapusin.org
}

\begin{abstract}
Abstrak
Pedoman Pendidikan Kapusin yang berlaku secara internasional, dan dijabarkan di jajaran (lokal) agar sesuai dengan kontes budaya dan zaman, merupakan sarana untuk mereformasi materi dan pola pendidikan Kapusin berkharisma. Pedoman ini membantu proses pembentukan saudara Kapusin generasi baru agar berperan aktif dan isnpsiratif di zaman aktualnya. Para saudara yang berpendidikan berlanjut berperan penting untuk menuntun para saudara berpendidikan awal, agar siap latih dan tetap belajar di zaman multikultur, perkembangan teknologi terutama bidang media sosial, serta pola hidup yang berubah dan baru. Injil Kristus yang dihidupi oleh St. Fransiskus adalah dasar pedoman pendidikan Kapusin di atasnya dibangun gagasan berharga dan pola pendidikan yang relevan. St. Fransiskus memesankan agar para saudara menghayati Injil terutama hidup bersaudara dengan love freely given, fidelity to Poverty and obedience to the Church. Pelaku aktif dan inspiratif di zaman aktual adalah pribadi berinegritas, matang dalam 5 dimensi: kharismatis, manusiawi, rohani, intelektual, dan misi. Pribadi yang berintegritas berpengaruh di konteks anthropological pluralism and the digital world (cyber-anthropology). Kekayaan berakar kharisma serta budaya berbeda perlu dipelajari, serta kemajuan bersayap baru dalam wajah teknologi baru khusunya teknologi media sosial, pantas digeluti secara bertanggung jawab. Anggur baru harus ditempatkan dalam kantong kulit baru. Dengan menghidupi dan mengobarkan nyala kharisma kapusin bernew mindset dalam new contexts, para saudara Kapusin generasi baru hidup bersuka cita untuk membangunkan dunia.
\end{abstract}

Kata-kata Kunci: pendidikan, kapusin, integritas, kharisma, bersaudara, kultur.

\footnotetext{
* Largus Nadeak, lisensiat dalam bidang Teologi Moral; lulusan Universitas Lateranensis Academia Alfonsiana, Roma; dosen Teologi Moral pada Fakultas Filsafat Unika St. Thomas, Sumatera Utara.
} 


\section{Pendahuluan}

Tulisan ini bernada spesial karena mengutarakan pendidikan Kapusin berkharisma yang merupakan satu ordo Lembaga Hidup Bakti (LHB), namun ide ini memuat rumus umum pendidikan anggota LHB, dan pendidikan imam secara umum. Pedoman Pendidikan Kapusin yang berlaku secara internasioan, Ratio Formationis OFMCap $^{1}$ yang dikeluarkan 08 Desember 2019 menjadi bahan inspiratif utama dalam tulisan ini untuk menyiapkan para kapusin generasi baru agar menjadi pelaku aktif dan inspiratif di zaman aktual mereka.

Ada beberapa gagasan ditonjolkan antara lain: 1) Pendidikan integral dengan memperhatikan 5 dimensi yang berkaitan yaitu, kharismatis, manusiawi, rohani, intelektual, dan misi; 2) Belajar berinterkulturasi di zaman anthropological pluralism and the digital world (cyber-anthropology); 3) Menghidupi kharisma dan menyebarkan nyalanya dengan bermisi. Setiap saudara adalah formator sekaligus formandi permanen agar anggur baru ditempatkan dalam kantong kulit baru.

\section{Menjumpai Kekuatan dalam Bentuk Baru}

Ide Michal Levin berdaya inspiratif agar setiap orang terlibat aktif di zamannya, "Bayangkan Anda tidak pernah mengemudikan mobil sebelumnya. Di desa Anda, yang Anda miliki hanyalah kuda dan pedati. Satu mobil muncul pada suatu malam di suatu lapangan. Tak seorang pun tahu harus berbuat apa. Akhirnya, karena melihat mobil itu mempunyai roda, orang-orang memastikannya sebagai semacam kendaraan. Maka mereka mengikatkannya pada satu regu kuda dan menariknya berkeliling. Orang-orang yang mengendarai kuda itu merasa bangga karena telah memecahkan masalah, dan sedang 'mengemudikan' mobil itu! Akan tetapi, tentu saja mereka tidak sedang melakukannya."2

\footnotetext{
${ }^{1}$ Ratio Formationis OFMCap, Living according to the Form of the Holy Gospel, Roma, 2019, hlm. presentasi.

${ }^{2}$ Michal Levin, Spiritual Intelligence, Membangkitkan Kekuatan Spiritual dan Intuisi Anda, Jakarta, PT Gramedia Pustaka Utama, 2005, hlm. 30.
} 
Mesin mobil beserta dayanya seharusnya menggerakkan mobil tersebut dan pengendara seharusnya mampu megendalikan setir sehingga mobil dikemudikan dengan tepat. Kreasi teknologis yang dihasilkan manusia di zaman aktualnya membawa manfaat signifikan kalau manusia secara bersama mengembangkan kecerdasan secara baru dengan renewing mindset dan mengaktualkan spiritualitas. Dengan bagus Kongregasi untuk Tarekat Hidup Bakti dan Serikat Hidup Kerasulan menggariskan panggilan untuk penghayat hidup bakti agar menghidupi ide baru dan kondisi baru dengan pesan: anggur baru harus ditempatkan dalam kantong kulit baru. ${ }^{3}$

\section{Revolusi Pendidikan}

Ratio Formationis OFMCap menggariskan bahwa pendidikan kapusin adalah the art of learning to be lesser brother. Pendidikan berisi seni pembentukan hidup berproses untuk menghidupi Injil Tuhan Yesus sebagai an authentic path to holiness. Ratio Formationis menyerap kekayaan edukatif dan pemuridan yang dihayati St. Fransiskus dari Assisi. Dia tidak menuntut saudara harus sempurna, tetapi "Francis encourages a sense of shared responsibility, values what is positive and avoids inducing a sense of guilt." "Accompaniment means creating opportunities that make responsibility, trust, and trasparency possible in every area." ${ }^{5}$ Menurut St. Fransiskus, pendidikan dan pemuridan yang benar berlangsung dengan menjadikan Kristus Sang Guru sebagai pusat hidup. St. Fransiskus menghayati pemuridan ini sehingga, "He was always with Jesus! Jesus is in his heart, Jesus on his lips, Jesus in his ears, Jesus in his eyes, Jesus is in his hands, he bore Jesus always in his whole body."

Satu pesan berharga dalam Injil adalah hidup bersaudara dengan menempatkan diri sebagai lesser brother (saudara dina). Penempatan diri sebagai saudara dina bisa berhasil kalau ada revolusi pendidikan yaitu

\footnotetext{
${ }^{3}$ Kongregasi untuk Tarekat Hidup Bakti dan Serikat Hidup Kerasulan, Anggur Baru dalam Kantong Kulit Baru, Jakarta, Dokpen KWI, Jakarta, 2018, no. 1.

${ }^{4}$ Ratio Formationis OFMCap, Living..., no. 147.

${ }^{5}$ Ratio Formationis OFMCap, Living..., no. 149.

${ }^{6}$ Ratio Formationis OFMCap, Living..., hlm. presentasi.
} 
belajar dari orang-orang miskin. ${ }^{7}$ "The poor are our teachers, when we take the risk of viewing reality from their point of view and make their priority our own."8 Para saudara belajar dari orang miskin karena pada mereka Kristus mengidentivikasikan diri-Nya. Para saudara mengikuti the poor and naked Christ sehingga menemukan bahwa kemiskinan-Nya membebaskan orang beriman dari ketamakan dan membimbing mereka pada misteri kebenaran.

Revolusi: Berangkat dari ongoing formation "Bangkit dan Berjalanlah" ke initial formation "Mari Mengobarkan Kembali Nyala Kharisma Kita”

Minister General Kapusin, Mauro Jöhri di periode pertama (2006-2012), pada awal pelayanannya bersama para Penasihatnya menyimpulkan bahwa hal yang paling penting diperhatikan dalam program mereka adalah pendidikan. Mereka menawarkan revolusi pendidikan dengan perhatian pertama justeru diberi pada ongoing formation (pendidikan berlanjut) karena persaudaraan berperan penting dalam pendidikan, dan setiap saudara adalah pendidik (tuntunmenuntun). Ide ini berformat revolusi karena beda dari keyakinan selama ini yang selalu mencari "kambing hitam" kekurangdewasaan seorang saudara secara pribadi dan bersama di initial formation. Dengan yakin mereka mengatakan bahwa krisis pendidikan awal, pada hakekatnya tergantung dari krisis pendidikan berlanjut.

Ide mereka berhubungan dengan krisis yang sedang dialami oleh beberapa penyandang Lembaga Hidup Bakti saat itu, yaitu hidup penghayat hidup bakti yang sudah berkaul kekal tidak sesuai dengan kharisma, dan 3 kaul tidak dihayati dengan baik. Mencuat ke permukaan secara internasional beberapa selibater tidak menghidupi kaul kemurnian yang tampak dalam tindakan kejahatan seksual. Untuk merealisasikan gerak transformasi, Minister General membuat Surat edaran agar para

\footnotetext{
${ }^{7}$ Pemeran pendidikan: Roh Kudus, Calon sebagai subjek utama dalam Formasi, Fraternitas Formasi, Tim Formasi, Orang Miskin.

${ }^{8}$ Ratio Formationis OFMCap, Living..., no. 174.
} 
saudara berangkat dari "Bangkit dan Berjalanlah"9 (tentang Pendidikan Berlanjut) ke "Mari Mengobarkan Kembli Nyala Kharisma Kita"10 (tentang Pendidikan Awal). Para saudara yang berpendidikan berlanjut berperan sebagai teladan dan penuntun para saudara berpendidikan awal (inisiasi). Di akhir pelayanan periode ke-2 (2012-2018) pada tahun 2018, Minister General, Mauro Jöhri dan Tim Pendidikan International menyelesaikan draf Ratio Formationis OFMCap (untuk semua Jajaran) yang harus dijabarkan di setiap Jajaran agar sesuai dengan konteks, sehingga kharisma kapusin berakar dan menyala di mana saja secara aktual.

\section{Revolusi: Pribadi Berintegritas}

Agar saudara bisa pelaku aktif dan inspiratif di zaman aktual kegiatan pendidikan menempa pribadi secara integral. Pendidikan berrevolusi pribadi berintegritas tidak cukup hanya mengulang-ulangi pengalaman St. Fransiskus (dulu), tetapi menginterpretasi pemahaman dan pengalaman asli (genuine) St. Fransiskus dalam konteks budaya baru di zaman aktual. Proses pendidikan karisma Kapusin pada setiap tahap pendidikan diracik (dari perspektif Kapusin) dalam lima (5) dimensi penting.

\footnotetext{
${ }^{9}$ Mauro Jöhri, Pendidikan Tetap, Surat Edaran Minister General, Roma, 2010. Ada beberapa pesan berharga dalam Surat Edaran ini, antara lain: Pendidikan tetap harus memberi sumbangan bukan hanya kepada saudara masing-masing tetapi juga kepada perkembangan seluruh persaudaraan. Tuhan sendiri berkata, "Bangkitlah dan berjalanlah!" (Mat 9,5). Hendaknya bangkit minat baru bagi para sudara berpendidikan tetap dan mendorong saudara agar ikut-serta pada kebaruan secara teratur. Hidup bakti merupakan suatu realitas terwujud dalam kemanusiaan dan zaman. Dalam pendidikan tetap ada kemauan membarui diri pada inti dan jantung pilihan hidup bakti: penyerahan diri dan pembaruan keahlian agar karya dilaksanakan secara kompeten dan terampil. Saudara dipanggil untuk merasa gembira atas teladan baik yang diterima dari saudara lain. Hal ini membuat kata-kata Mazmur 133 sungguh hidup, “Alangkah baik dan menyenangkan tinggal bersama sebagai Saudara”.

${ }^{10}$ Mauro Jöhri, Mari Mengobarkan Nyala Kharisma Kita, Surat Edaran kepada Semua Saudara seOrdo tentang Pendidikan Awal, Roma, 2008. Yang perlu diperhatikan dan disampaikan pada kapusin generasi baru antara lain: penjelmaan nilai dan kharisma kapusin yaitu hidup persaudaraan, kedinaan, kontemplasi, dekat pada orang miskin, dan pembaruan tetap. Hidup religius dihayati pada waktu, tempat, dan kebudayaan yang sangat berbeda satu sama lain. Pendidikan awal merupakan tanggung jawab bersama. Tantangan pendidikan yang ada dihadapi dalam semangat persaudaraan dan iklim kebersamaan.
} 


\section{Dimensi karismatis: Karunia Menjadi Saudara Dina ${ }^{11}$}

St. Fransiskus pembaca Injil dan pembaca alam. St. Fransiskus menghidupi Injil dan membaca kehendak Allah di alam ciptaan sehingga dia bahagia berelasi dengan semua ciptaan yang disebutnya sebagai saudara-saudari (manusia, makhluk hidup, dan benda "mati"). Spiritualitas Kapusin mengalir dari penghayatan St. Fransisku dan menjabarkannya dalam nyala kharisma yang harus dihayati dan dikobarkan yaitu brotherhood, minority, contemplation, mission, reform. Uraian nyala kharisma ini akan diurai secara singkat di bagian kapusin berkharisma.

\section{Dimensi Manusiawi: Belajar Menjadi Saudara bagi Semua ${ }^{12}$}

Antropologi fransiskan menekankan karakter dinamis manusia. Manusia dicipta menurut gambar Allah. Kegiatan pendidikan hendaknya mengasimilasi dan mentransformasi nilai-nilai dari manusia dicipta menurut gambar Allah dan dari makna persaudaraan yang diajarkan Yesus. Saudara Kapusin dipanggil untuk cakap dalam kemanusiaan dan persaudaraan (expert in humanity and brotherhood), sehingga tahu membaca dan menafsirkan pengharapan dan ketakutan zaman aktual. Kematangan manusiawi tampak dalam: mengenal diri, menerima realitas, mampu memberi diri. Pendidikan membantu saudara untuk paham serta memiliki pengalaman relasi afektif, serta mentransformasi dunia secara bersama. Identitas bersaudara dibangun dengan relasi saling memperhatikan, saling berbelaskasih, dan memaafkan. Persaudaraan dibangun di dalamnya setiap pribadi memiliki affective and psychosexsual maturity, yang mensuasanakan bersaudasra afektif dengan mamahami energi seksual dalam kebersamaan selibat. Persaudaraan tidak meniadakan individu justru melindungi setiap saudara agar tidak jatuh pada individualisme.

\footnotetext{
${ }^{11}$ Ratio Formationis OFMCap, Living..., no. 62-73.

12 Ratio Formationis OFMCap, Living..., no. 74-85.
} 
Dimensi Rohani: Belajar untuk Menginginkan ${ }^{13}$

Menginginkan itu suatu seni. Kegiatan pendidikan menjadikan gerakan pengalaman dari superfisial sampai pada yang esensial. Pendidikan mengarahkan keinginan untuk mendalami dan menginterpetasi hidup rohani St. Fransiskus dalam hidup sakramental, devosi dan kekudusan agar relevan. Daya rohani khusunya kedinaan diperoleh dari Yesus yang merendahkan diri seturut teladan St. Fransiskus. Sebagai manusia injili St. Fransiskus mendengar Sabda Yesus (undangan kemuridan), dan dia mengikuti Dia dalam perjalanan keindahan, kebebasan, dan kontemplasi.

\section{Dimensi Intelektual: Belajar Berpikir dengan Hati ${ }^{14}$}

Berpikir dengan hati membentuk pribadi menjadi expert in humanity and in brotherhood. Dimensi intelektual tak boleh direduksi pada kecerdasan intelektual dan tekstual. Dalam dimensi ini diperhatikan kegiatan memahami realitas dengan benar agar tumbuh cinta dan kearifan sehingga tidak ada ketakutan dan apatisme, sebaliknya yang bertumbuh compassion dan kasih. Pengalaman bersaudara mengajari setiap saudara untuk menghargai saudara dengan anugerah personalnya. Pendidikan membantu para saudara untuk bersaudara secara afektif, serta mentransformasi dunia secara bersama. Kontemplasi personal dan bersama merupakan sumber pengetahuan, membuat mata budi dan hati menemukan kebenaran dan kebaikan, membuat para saudara berdaya menyembuhkan keterlukaan dan membentuk persaudaraan yang berbelarasa.

Dimensi Misioner: Belajar Mewartakan dan Membentuk Persaudaraan ${ }^{15}$

Permandian menjadikan orang kristen menjadi murid dan misionaris. Panggilan eksistensial gerejawi para saudara kapusin adalah bersaudara dan bermisi. Para saudara kapusin bergerak dalam misi Gereja. Hidup sebagai saudara dina adalah panggilan utama, dan

\footnotetext{
${ }^{13}$ Ratio Formationis OFMCap, Living..., no. 86-101.

${ }^{14}$ Ratio Formationis OFMCap, Living..., no. 102-114.

15 Ratio Formationis OFMCap, Living..., no. 115-127.
} 
merupakan elemen pertama bermisi. Para saudara menjadi misionaris saat hidup sebagai saudara dina, dan ketika mewartakan Injil dengan berjumpa dengan sesama dan juga saat memanusiakan bumi ini. Dengan perjumpaan itu terbentuk ikatan persaudaraan. Setiap tahap formasi harus menanamkan semangat misi. Perlu ditanamkan pemahaman realitas zaman di Gereja lokal dan universal. Misi Gereja mencipta oase kemanusiaan dan bergerak demi kesejahteraan bersama dan membangun damai. Misi utama saudara dina adalah menjumpai sesama sebagai saudara, menemani orang miskin, menghargai budaya berbeda, keadilan sosial, dan ekologi.

\section{Revolusi: Zaman Anthropological Pluralism and the Digital World (Cyber-Anthropology)}

Sekarang terjadi gerakan demografi panggilan dan tempat kharisma bernyala. Pantas dibanggakan bahwa di Eropa (dunia Barat) berkembang iman dan panggilan, dan dari sana hal itu menyebar ke seluruh dunia. Lama durasi dan banyak ide spiritual berkiblat ke Barat. Saat ini nyata dialami pergeseran. Iman dan panggilan bertumbuh subur di Asia dan Afrika. Budaya Asia dan Afrika yang sangat kaya variasi, sangat cocok sebagai kondisi nyala kharisma untuk berkobar. Di samping budaya/kultur tidak ada lagi yang dominan, kesadaran juga berkembang dengan meyakini bahwa tidak ada budaya yang dominan. Pengakuan makin dominan bahwa ada banyak budaya (multi kultur) yang sama-sama memiliki banyak nilai. Pada rentang waktu lalu beberapa ordo atau kongregasi dihuni oleh biarawan/biarawati dari satu suku dominan, sehingga kebiasaan lokal di ordo/kongregasi tersebut adalah kebiasaan budaya yang dominan tersebut. Sekarang kenyataan dan cara pandang berbeda. Kehadiran penghuni yang bervariasi latar belakang budaya dan juga kesadaran multi kultur membuat kebersamaan menjadi indah. ${ }^{16}$

Identitas kharismatik kapusin bisa diterima dan dihidupi para saudara di budaya dan konteks berbeda. Kebersamaan multi kultur yang indah akan menjadi terikat kuat dan menjadi kekayaan sinergis kalau terjadi interkulturasi. Setiap saudara berusaha menggali kekayaan nilai

${ }^{16}$ Ratio Formationis OFMCap, Living..., Apendiks, no. 2-3. 
budayanya (inkulturasi) dan juga menghargai budaya lain. Perbedaan budaya dan usaha saling belajar memahami budaya berbeda membuat hidup bersaudara sebagai saksi interkulturasi. Kesaksian interkulturatif ini memanggil para saudara untuk menggali dan mempelajari budaya setempat di mana saudara melayani sehingga nyata bahwa tempat tersebut kaya nilai persaudaraan, misi, dan cinta alam. ${ }^{17}$

Di samping mempromosikan usaha interkulturasi, Ratio Formationis menyiapkan para saudara agar berperan baik, aktif dan inspiratif di kenyataan kontekstual budaya baru yaitu digital world (cyber-anthropology). Persiapan yang apik untuk berperan di budaya baru akan menghasilkan para sudara kapusin generasi baru yang update dan bersuka cita. Anggur baru ditempatkan dalam "kantong kulit baru". Keterlibatan penyebaran nilai rohani, promosi damai dan keadilan akan menghasilkan persaudaraan berasa baru di konteks baru dengan menggunakan sarana maju (aktif mendownload tetapi lebih aktif mengupload gagasan kreatif dan inspiratif serta mengkases pesan bernilai dan berharga) secara bertanggung jawab. Rancangan pembinaan harus memberikan perhatian khusus pada usaha pengintegrasian pikiran dan tindakan dalam bahasa digital yang baru secara kritis, kreatif, dan bertanggung jawab.

\section{Berakar dan Bersayap}

Rabbi Eugene Levy memberi ide inspiratif pada orang tua dalam mendidik anak,

"As you bring up your children,... you want them to have roots and wings. You want them to feel grounded and secure, to feel connected with things that count. But you also want them to think new thoughts and feel new feelings, to be able to fly in new directions." 18

Akar-akar dan sayap-sayap merupakan metapor. Kalau dihubungkan dengan kehidupan kristen, "Roots indicate a sense of spiritual

\footnotetext{
${ }^{17}$ Formationis OFMCap, Living..., Apendiks, no. 6-7.

18 Pendapat Rabbi Eugene Levy dalam Jay B. McDaniel, With Roots and Wings, Christianity in an Age of Ecology and Dialogue, New York, Orbis Books 1995, hlm. 23.
} 
wellbeing that comes from being richly connected with the heavens and the earth, and with the God in whom they are enfolded. And I use wings to indicate a sense of exploration and freedom that comes from being open to new futures, which are themselves a dimension of God's ongoing life."19

Ide edukatif ini menjadi inspirasi untuk mendidik para saudara generasi baru, agar mereka berakar dan bersayap. Dengan akar-akar: Sabda Allah, konstitusi ordo yang mengandung kekayaan spiritualitas, dan kharisma kapusin, para saudara bersayap misi: arah baru, imaginasi/impian sehat, kreativitas bermakna, kebebasan sejati, menjadi pelaku aktif dan inspiratif di zaman aktual mereka.

\section{Kapusin Berkharisma}

Identitas para saudara kapusin adalah saudara dina bagi semua. Nyala kharisma yang tampak dalam penghayatan, dan harus dikobarkan adalah: brotherhood, minority, contemplation, mission, reform. Tugas dan panggilan saudara adalah menjadi saudara dina bagi semua ciptaan sebagaimana Yesus menjadi Saudara bagi semua. Relasi bersaudara memberi ruang bagi perkembangan saudara secara human dan spiritual. Persaudaraan adalah tempat belajar hidup, berkontemplasi, berefleksi, mempertimbangkan dengan jernih dan membuat keputusan secara bersama dalam persaudaraan. Persaudaraan tidak meniadakan individu justru melindungi setiap saudara agar tidak jatuh pada individualisme. Dasar kedinaan Kapusin adalah Yesus yang merendahkan diri. Anyone who wants to be a lesser brother must give up any kind of domination. Kedinaan membuat para saudara berpikiran terbuka untuk menjadi saksi persaudaraan. Kontemplasi memampukan para saudara untuk melihat sesuatu dengan mata Allah. Kontemplasi menjernikan mata kepala, mata budi, mata hati dan terlebih mata iman untuk melihat mereka yang beridentivikasi dengan Yesus. Tanpa kontemplasi tak ada persaudaraan. Dengan kontemplasi para saudara mengakui kebaikan Allah hidup di kebersamaan. Misi Kapusin adalah mempromosikan hidup bersaudara

${ }^{19}$ Jay B. McDaniel, With Roots and Wings..., hlm. 3-4. 
yang dihayati dengan pemberian diri, serta pergi ke tempat yang tidak diingini orang lain. Pembaharuan Kapusin bukan suatu sejarah masa lalu, melainkan suatu sikap hidup yang menjadi bagian identitas karismatis persaudaraan. Keinginan untuk membarui diri terus-menerus mengundang para saudara memandang ke depan, dengan menghindarkan nostalgia masa lalu tetapi berani menerima risiko-risiko yang menyertai perjalanan menuju masa depan yang belum tertulis. Para saudara tidak tinggal di kemapanan palsu, tetapi bangkit dan berjalan (bergerak) berdaya injili diinspirasi oleh pemahaman St. Fransiskus. ${ }^{20}$

\section{Kapusin Berimisi}

Hidup menggereja adalah menghayati Injil dan mewartakan Kristus. Dengan tetap mengindahkan hak Sri Paus untuk menggunakan pelayanan Ordo demi kebaikan Gereja universal, pelaksanaan kegiatan kerasulan mana pun berada di bawah kuasa Uskup keuskupan, darinya saudara-saudara menerima kewenagan yang perlu, sesudah disetujui oleh minister mereka. ${ }^{21}$

"We are missionaries when we announce, as brothers, the Gospel, humanise the earth by creating bonds of broteherhood."22 Misi kapusin dimulai dalam persaudaraan, di dalamnya setiap saudara penghayat kharisma tersebut bertemu dengan saudara lain. Mengikuti alur spiral para saudara dengan menghidupi kharisma secara otentik pergi mempromosikan persaudaraan yang dihayati dan mengobarkan nyala kharisma ke mana saja, terutama ke tempat orang tidak mau pergi, ke kondisi riskan orang lain tidak rela pergi. Saudara berusaha membuka pintu di keterpencilan dan kesulitan agar harapan bernafas ${ }^{23}$ Setiap

\footnotetext{
${ }^{20}$ Ratio Formationis OFMCap, Living..., no. 62-73

${ }^{21}$ Konstitusi Saudara Dina Kapusin, Roma, 2015, no. 148.

22 Ratio Formationis OFMCap, Living..., no. 127.

${ }^{23}$ Panggilan pergi ke tempat yang tidak didatangi orang lain dirumuskan dalam Instruksi Kongregasi untuk Tarekat Hidup Bakti dan Serikat Hidup Apostolik, "Banyak tarekat tradisional dan baru membawa kaum hidup bakti pada tempat di mana orang lain tidak mendatangi. Tahun-tahun terakhir kaum hidup bakti mampu meninggalkan keamanan ha yang telah dikenal untuk mempercayakan diri pada tempat-tempat dan karya yang tidak dikenal. Berkat pentakdisan yang utuh mereka nyatanya bebas menapaki di mana saja ada kebutuhan yang kritis. Instruksi Kongregasi untuk Tarekat Hidup Bakti dan Serikat Hidup Apostolik, Bertolak Segar dalam Kristus: Komitmen Hidup Bakti yang Dibaharui di
} 
saudara menjadi saudara bagi sesama, dan pergi untuk bertemu dengan siapa saja karena mereka adalah saudara. ${ }^{24}$ Pertemuan bisa terjadi di tempat "baru" tertentu agar jiwa bersaudara injili yang dihayati para saudara mekar. Pertemuan bersaudara bisa juga di kondisi tertentu, antara lain di budaya berbeda di agama berbeda dengan menghargai budaya dan agama mereka (interkulturasi).

"Kita membaktikan diri khususnya kepada mereka yang jauh dari iman dan praktik keagamaan, dan juga kepada mereka yang tidak menerima pelayanan pastoral biasa karena situasi hidupnya, seperti orang muda yang mengalami krisis hidup kristen, para perantau, pekerja dan orang yang tertekan kesulitan ekonomi, atau terkena diskrimansi dan penganiayaan karena alasana apa pun... mari berusaha membangun dialog keselamatan dengan orang beragama lain dan dengan mereka yang tidak beriman di tempat hidup dan ke mana kita diutus... mari hidup dekat pada masyarakat dengan hati sederhana, dan sungguh-sungguh berlaku sebagai saudara dina sejati dalam gaya hidup dan cara berbicara." 25

Hidup bersaudara di rahim Allah Maharahim membutuhkan usaha dan jiwa dina. Menurut St. Fransiskus, "Perfect joy: if your heart is not troubled; if you perserve in your vocation to go on being a brother to all, without claiming anything as your own (even what you think you deserve), then you will have defeated the shadow of sadness, for ever." 26

Bermisi juga memasuki kondisi baru termasuk kemajuan teknologi yang memudahkan penghayatan kharisma dan mengobarkannya. Mass media menjadi sarana mendalami kharisma serta berbagi pengalaman, pengetahuan, pekerjaan dan minat. Media social

\footnotetext{
Melenium Ketiga, Jakarta, Dokpen KWI 2004, no. 36. Dengan jelas Ratio Formationis menggariskan pesan yang sama, "As Capuchins we continue to be sent to places where noone else wishes to go, to commit ourselves to create together oases of brotherhood in conflict zones and distant outposts: privileged spaces where we live out the gift of freelygiven service." Ratio Formationis OFMCap, Living..., no. 72.

${ }^{24}$ Paus Pransiskus, Ensiklik Fratelli Tutti, Roma, 2020, no. 77.

${ }^{25}$ Konstitusi Saudara Dina Kapusin..., no. 149.

${ }^{26}$ Ratio Formationis OFMCap, Living..., no. 52.
} 
dipergunakan menurut prinsip-prinsip injil agar terhindar dari resiko kecanduan yang bisa melemahkan relasi fraternal dan karya pastoral.

"Mari menyebarkan warta Kristus juga dengan mempergunakan alat komuniaksi sosail, yang menawarkan peluang besar bagi penginjilan... Juga perlu bahwa semua saudara secukupnya dibina dalam pemakaian alat-alat komunikasi sosail dengan penuh tanggung jawab.",27 Kemajuan dan perubahan akan berjalan terus dari zaman ke zaman dan dari generasi ke generasi. Para saudara hendaknya berperan sebagai pelaku aktif dan inspiratif di zamannya?

\section{Penutup}

Pendidikan kapusin memformat hidup para saudara agar berjiwa pembaru. Pola penghayatan tidak cukup hanya mengulang-ulangi pengalaman St. Fransiskus masa lalu, tetapi meningterpretasinya, to recreate his genuine insights in new culture contexts.

Saudara Kapusin berpribadi berintegritas atau utuh dalam dimensi kharismatis, manusiawi, rohani, intelektual, dan misi; dengan identitas saudara dina berkharisma: bersaudara, dina, kontemplasi, misi, dan reformasi mengalami secara baru dan nyata penghayatan St. Fransiskus, "Jesus in his heart, Jesus is in his mouth, Jesus is in his ears, Jesus in his eyes, Jesus in his hands." 28 Pembarui diri diterapkan secara berkelanjuta agar setiap saudara berperan aktif dan inspiratif di zaman interkulturasi dan di pola hidup berubah, sehingga berdaya membangunkan dunia. ${ }^{29}$

$$
===0000====
$$

\footnotetext{
${ }^{27}$ Konstitusi Saudara Dina Kapusin..., no. 156.

${ }^{28}$ Ratio Formationis OFMCap, Living..., hlm. presentasi.

${ }^{29}$ Paus Fransiskus, "Pesan Video Paus Fransiskus untuk Vigili Doa di Basilika Santa Maria Maggiore pada Pembukaan Tahun Hidup Bakti, dalam Kongregasi untuk Tarekat Hidup Bakti dan Serikat Hidup Kerasulan”, Tabun Hidup Bakti, Jakarta, Dokpen KWI, 2015, hlm. 56.
} 
Logos, Jurnal Filsafat-7eologi, Vol. 18, No. 1. Januari 2021

\section{DAFTAR PUSTAKA}

Jöhri, Mauro. Mari Mengobarkan Nyala Kharisma Kita, Surat Edaran kepada Semua Saudara se-Ordo tentang Pendidikan Awal, Roma, 2008.

Jöhri, Mauro. Pendidikan Tetap, Surat Edaran Minister General, Roma, 2010.

Kongregasi untuk Tarekat Hidup Bakti dan Serikat Hidup Kerasulan, Instruksi Bertolak Segar dalam Kristus, Komitmen Hidup Bakti yang Dibaharui di Milenium Ketiga, Jakarta: Dokpen KWI, 2004

Kongregasi untuk Tarekat Hidup Bakti dan Serikat Hidup Kerasulan, Tahun Hidup Bakti, Jakarta: Dokpen KWI, 2015.

Kongregasi untuk Tarekat Hidup Bakti dan Serikat Hidup Kerasulan, Anggur Baru dalam Kantong Kulit Baru, Jakarta: Dokpen KWI, Jakarta, 2018.

Konstitusi Suadara Dina Kapusin, Roma, 2015.

Levin, Michal. Spiritual Intelligence, Membangkitkan Kekuatan Spiritual dan Intuisi Anda, Jakarta: PT Gramedia Pustaka Utama, 2005.

McDaniel, Jay B. With Roots and Wings, Christianity in an Age of Ecology and Dialogue, New York: Orbis Books, 1995.

Paus Pransiskus, Ensiklik Fratelli Tutti, Roma, 2020.

Ratio Formationis OFMCap, Living according to the Form of the Holy Gospel, Roma, 2019. 